\title{
INTERNATIONAL ASTRONOMICAL UNION SYMPOSIA
}

Published by the Astronomical Society of the Pacific

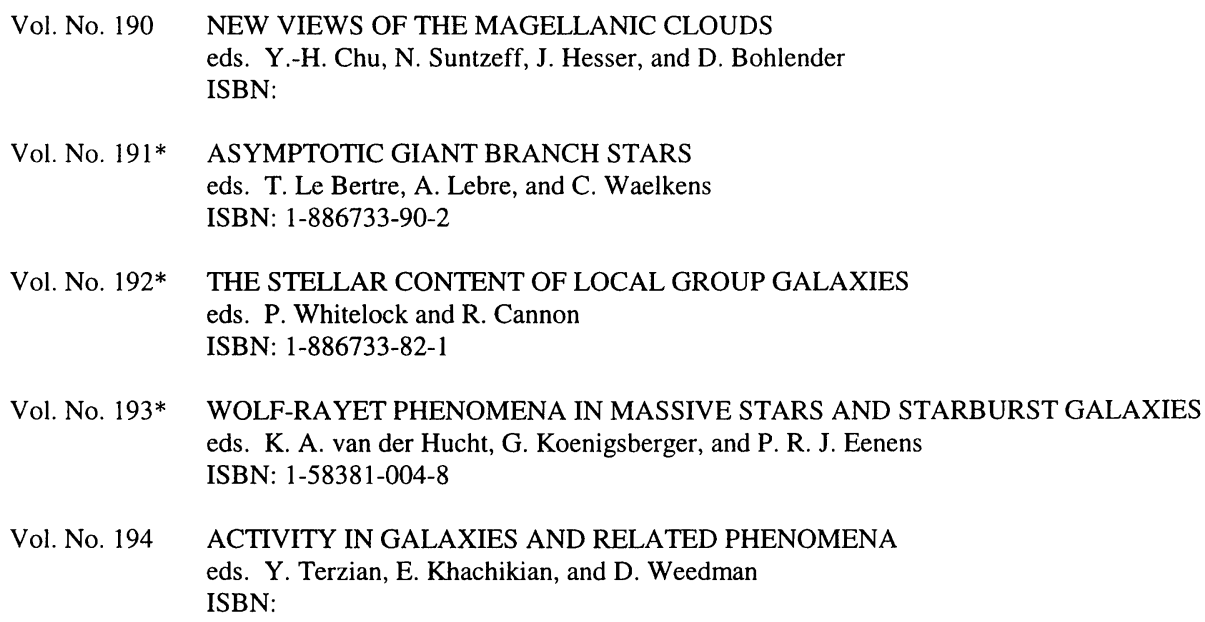

Vol. No. 193* WOLF-RAYET PHENOMENA IN MASSIVE STARS AND STARBURST GALAXIES eds. K. A. van der Hucht, G. Koenigsberger, and P. R. J. Eenens ISBN: $1-58381-004-8$

Vol. No. 194

Please note volumes with asterisk $\left(^{*}\right)$ and ISBN are either in the process of being published or already printed as of May 1999.

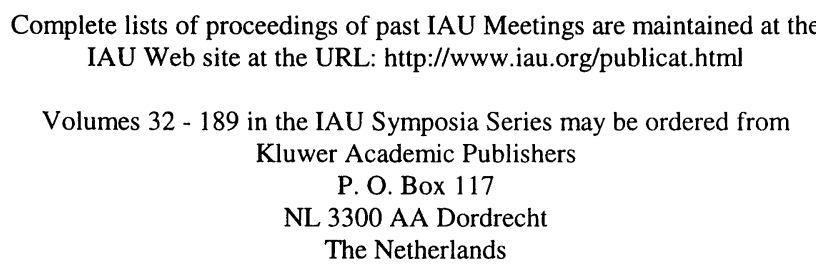

\section{EDITORIAL/PUBLISHING OFFICE:}

Managing Editor

PO Box 24463

211 - KMB

Brigham Young University

Provo UT 84602-4463

USA

$\begin{array}{ll}\text { (801) 378-2298 } & \text { Phone } \\ \text { (801) 378-2265 } & \text { Fax } \\ \text { pasp@astro.byu.edu } & \text { E-mail }\end{array}$

\section{CATALOG/BOOK ORDERS:}

IAU Publications

390 Ashton Avenue

San Francisco CA 94112-1722

USA

$\begin{array}{ll}\text { (415) 337-1100 } & \text { Phone } \\ \text { (414) 337-5205 } & \text { Fax } \\ \text { catalog@aspsky.org } & \text { E-mail }\end{array}$


ISBN $1-58381-004-8$

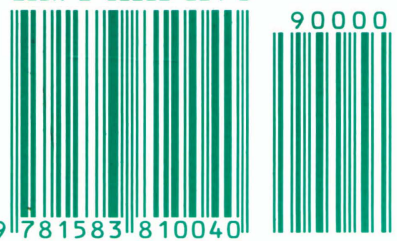

https://doi.org/10.1017/S0074180900206864 Published online by Cambridge University Press 